\title{
Research on Contract Coordination in the Manufacturing Supply Chain Given China's Work Safety Constraints
}

\author{
Zongkang Yang $\mathbb{D}^{1},{ }^{1}$ Qiang Mei $\mathbb{D}^{1},{ }^{1}$ Qiwei Wang $\mathbb{D}^{2},{ }^{2}$ Suxia Liu $\mathbb{D}^{1},{ }^{1}$ and Jingjing Zhang $\mathbb{D}^{1}$ \\ ${ }^{1}$ School of Management, Jiangsu University, Zhenjiang 212013, China \\ ${ }^{2}$ College of Economic and Management, Zhengzhou University of Light Industry, Zhengzhou 450002, China
}

Correspondence should be addressed to Qiang Mei; qmei@ujs.edu.cn

Received 15 April 2021; Revised 7 September 2021; Accepted 28 September 2021; Published 31 October 2021

Academic Editor: Saray Shai

Copyright (C) 2021 Zongkang Yang et al. This is an open access article distributed under the Creative Commons Attribution License, which permits unrestricted use, distribution, and reproduction in any medium, provided the original work is properly cited.

\begin{abstract}
With supply chain management's increasing importance in work safety, this paper establishes the leading enterprise with core enterprises as work safety units. These guide the small and medium-sized enterprises within the supply chain to focus on improving work safety according to the leading position of the supply chain's core enterprises. Therefore, the Stackelberg game model is applied to build and explain supply chain node-enterprises' optimal centralized and decentralized operational decisions. This research was conducted in the context of enterprise work safety constraints' influence on the manufacturing supply chain's equilibrium results. It also reveals the necessity in supply chain node enterprises' contract coordination design by comparing the two decision models' equilibrium results. Ultimately, the manufacturing supply chain's overall profit and work safety can reach a level that includes centralized decisions through revenue- and cost-sharing contracts. Furthermore, profits to the supply chain's node enterprises also improve, and a Pareto optimality is achieved. An enlightened management demonstrates the importance of core enterprises' leading position in the supply chain, and the supply chain node enterprises' levels of work safety, product demand, and total profit can be promoted through revenue- and cost-sharing contracts.
\end{abstract}

\section{Introduction}

As economic globalization and production socialization have expanded, enterprises' dependence upon production and operational activities has strengthened. Thus, future competition among enterprises includes both market- and supply chain-based competition [1]. Supply chain safety management is an important concept based on modern enterprise management teams' needs. Compared with small and medium-sized enterprises (SMEs), the supply chain's core enterprises have more advanced work safety, technological, and management means, and are in a dominant position in the supply chain. More social responsibility should be undertaken to improve the entire supply chain's work safety $[2,3]$. Simultaneously, SMEs' order-dependent characteristics compel them to adopt positive work safety measures; in particular, core enterprises in the supply chain have safety standards and work safety regulations that can attract SMEs' attention toward such measures. To enhance the reliability of the research background, we conducted a field study on supply chain work safety management at General Electric (GE) company in August 2020, which was aimed at effectively and sustainably improving suppliers' occupational safety and health, bringing about a green transition, promoting core competitiveness, transforming passivity to initiative, and achieving a win-win proposition by reducing costs on both sides to remain competitive.

Core enterprises' participation in SMEs' manufacturing and work safety management closely relates to their own interests. On the one hand, core enterprises see accidents as contingent, small-probability events, with indirect impacts, leading them to tend to ignore supply chain safety. At the same time, they only participate in SMEs' work safety management to fulfill a higher level of social responsibility. As this is not mandatory or legally binding, core enterprises with a weak sense of social responsibility are less willing to 
take the initiative to regulate SMEs, especially under weak external pressure. On the other hand, the trust relationship between core enterprises and SMEs can be sporadic, communication may be blocked, manager's responsibilities may be unclear, management may lack the means to conduct socially responsible activities, and there may be asymmetry in their work safety information. When multiple suppliers operate at the same level, core enterprises may experience difficulty in effectively implementing occupational health and safety management controls [4]. Therefore, there is an interactive game relationship between the core enterprise and SMEs in the supply chain work safety management. The core enterprise occupies the dominance and control in the game with manufacturing SMEs. The decision-making behavior of the core enterprise will affect the decision-making behavior of SMEs and the core enterprise is the maker of supply chain transaction rules.

Compared with other game models and research methods, the Stackelberg game is a two-stage complete information dynamic game, which can reflect the real-time interaction between supply and demand. Both sides choose their own strategies according to each other's possible strategies to maximize their interests in each other's strategies to achieve Nash equilibrium. Therefore, to explore the conduction effect of core enterprises participating in the work safety management of manufacturing SMEs, the paper is provided with the Stackelberg game. The Stackelberg game has relative advantages in dealing with the data onto real-time supply and demand interaction and the possible misinterpretation of the analysis results. It is suitable for the appropriate and in-depth analysis and interpretation of the interaction of supply chain node enterprises.

Meanwhile, this study offers a contract coordination design that strengthens the role of core enterprises in leading SMEs within the supply chain work safety management by the Stackelberg game model while filling the gap that concentrates the independent effect of SMEs' safety issues and supply chain work safety management through the numerical simulation.

Therefore, it is not only of great academic significance but also enlightening for safety management to establish a leading enterprise in the supply chain with core enterprises as work safety units. This would be based on the core enterprises' leading position in the supply chain, as they can guide the supply chain's SMEs to focus on a model and analysis to improve work safety.

\section{Literature Review}

According to the literature review, the existing relevant research mainly focuses on four aspects: firstly, research on the impact of safety accidents in manufacturing SMEs; secondly, research on the motivation of core enterprises of the supply chain participating in work safety management of SMEs; thirdly, research on the work safety behavior of the enterprise from the perspective of supply chain; fourthly, research on supply chain contract coordination.
SMEs suffer from safety weaknesses that cause work safety and occupational health issues. Supply chain management has shown increasingly significant meaning in enterprise production management, especially in its application in work safety [2]. Currently, many shortcomings still exist on a microeconomic level in the manufacturing supply chain, such as some SMEs' short-sightedness, lack of social responsibility and business ethics, the existence of major environmental pollution, work safety accidents, problematic occupational safety and health, and product quality and safety issues during production, each of which may increase the risk of supply chain interruption $[5,6]$. Furthermore, these could lead to a loss of brand and reputation among related enterprises in the supply chain, or even lead to their closure [7]. Among the many supply chain risks, occupational safety and health problems are particularly serious among SMEs, which account for $99 \%$ of China's enterprises. This is especially the case after the supply chain's core enterprises outsource their specialized businesses to SMEs, as the former may risk interrupting business activities caused by SMEs' problematic work safety and occupational health hazards [8-10]. Some serious problems still generally exist in China's manufacturing industry, such as a poor working environment, child labor, and violation of workers' personal rights and interest [11]. To complete orders in the shortest possible time, SMEs force workers to continuously work excessive hours, which increases employees' occupational hazards; these businesses also tend to ignore work safety management processes to meet production deadlines, which increases the hidden risk of accidents [12]. For example, a supplier-manufacturer in the "Poison Apple" case used toxic $\mathrm{n}$-hexane instead of alcohol to wipe cell phone screens to reduce costs, but poisoned more than 100 employees. Clearly, Apple failed to consider the occupational safety and health of enterprises in the supply chain, and exposing such events has attracted attention from the media as well as the public [13]. Similarly, occupational health and work safety incidents can occur in SMEs, such as Samsung suppliers' use of child labor, Foxconn's sweatshop, and the 2014 factory explosion in Kunshan, China. These all caused substantial economic and reputational damages to other enterprises in the supply chain.

As core enterprises play a leading role in the supply chain network, they have long exploited the supply chain's SMEs for profit. This renders their own safety investments insufficient; specifically, as employees' occupational health and safety conditions are of concern, "double marginalization" can easily occur between the core enterprises and SMEs [14]. Supply chain node-enterprises involve a community of interests; as long as any of them has a work safety accident or an event affecting occupational health, a supply chain risk similar to the "Poison Apple" event may occur, which could create a crisis throughout the entire supply chain. Therefore, the supply chain's occupational safety and health management has also attracted the concern and attention of many relevant interest groups, while scholars are also constantly calling on the government and public administrators to strengthen their governance of supply chain work safety behaviors in particular $[15,16]$. Furthermore, core 
enterprises require small and medium-sized suppliers to meet their social responsibility and focus on occupational health and safety [17] while sharing benefits and costs $[18,19]$. Therefore, relevant supply chain research presents an urgent need for works that examine how core enterprises can further enact occupational safety and health procedures in the supply chain, design contracts to coordinate the distribution of profits between core enterprises and SMEs, and alleviate the separation of revenue and input cost subjects in manufacturing supply chain node enterprises through safe production processes. Ultimately, such analyses will compel more SMEs to enhance their occupational safety and health management and reduce industrial injuries and occupational diseases, which will consequently improve the occupational health and safety in the overall supply chain system.

Research on supply chains' impacts on occupational safety and health behaviors $[20,21]$ has revealed that enterprises are less likely to volunteer preventive management initiatives without external regulatory pressures, and that supply chains can lead SMEs to strengthen occupational health and safety management [22-24]. Many scholars have also analyzed the influence of various subjects in the supply chain on enterprises' safety behaviors. Based on the influence of the enterprise's reputation and the trust from its partners, the enterprise will be willing to improve its safety behavior according to the supply chain contract, thus reducing occupational safety risks $[25,26]$. Core enterprises are not limited to ensuring work safety in the entire supply chain by standardizing enterprises' internal and safety management behaviors but must also supervise and standardize the behaviors of other SMEs in the supply chain. Therefore, strengthening core enterprises' leading role in social responsibility shows a necessary trend [15]. A survey by Laari et al. [27] confirmed that manufacturers may react to customers' pressure by transferring upstream supply chain requirements and either cooperating or monitoring suppliers' environmental performance. Moreover, Hsueh et al. $[28,29]$ combined corporate social responsibility (CSR) with supply chain coordination to innovate revenue-sharing contract; this was subsequently embedded into the enterprise's CSR to coordinate a dual-layer supply chain. The results demonstrate that this not only improves CSR performance and overall supply chain profits but also ensures that both partners will get benefits.

Furthermore, many supply chain management circumstances are caused by a range of nonmarket external pressures, for instance, policies and laws, social responsibility, regulatory reviews, and global supply chain development, among others; thus, market-based business motivation is needed to encourage core enterprises to exploit this potential [16]. However, some core enterprises transfer the risk of social responsibility to their relevant stakeholders in the supply chain through unreasonable contracts, which has increasingly compelled scholars to research supply chain contract coordination. For example, Cruz [30] established a dynamic model for supply chain network analyses that incorporated enterprises' social responsibility, which provides a reference for examining both supply chain networks and enterprises' social responsibility. Hafezalkotob [31] posited that according to the Stackelberg game, the government's environmental protection and tendency toward social responsibility significantly influence the government's revenue and supply chain members' profits. Li et al. [32] proposed a novel Stackelberg game-based optimization framework for the optimal scheduling of integrated demand response (IDR)-enabled integrated energy systems with uncertain renewable generations to balance the interests of integrated energy operator (IEO) and users. Song and Gao [29] observed that the revenue-sharing contract will make an important influence in coordinating the benefit distribution between a supply chain's upstream and downstream enterprises, and can effectively improve green supply chains' overall performance. Ghosh and Shah [33] analyzed a secondary supply chain composed of manufacturers and retailers, discussed how decentralized decisions influence products' green levels in the bargaining process, and then proposed a contract-coordination mechanism. Zhang et al. [34] established a dynamic model to develop supply chains in a long-term strategic perspective. The results indicate that while both supply chain types are less efficient than the static supply chain, a dynamic model can improve supply chain efficiency and the manufacturer's profit ratio. Kannan et al. [35] proposed a fuzzy criterion method to help manufacturers select the greenest and safest suppliers, with a numerical application provided to prove the method's validity. Other scholars have also coordinated supply chain improvement strategies through revenue-sharing contracts and cost-sharing mechanisms that increase the supply chain's overall profit $[36,37]$.

In summary, core enterprises are a mainstay in influencing the safety behaviors of enterprises in the supply chain. The constraints from core enterprises can effectively regulate the social responsibility behaviors of specific enterprises in the supply chain, and gather knowledge in the fields of product quality, environmental governance, occupational health, and work safety. Simultaneously, scholars $[31,33,36,37]$ have also researched the coordination of supply chain enterprises' social responsibility contracts, but most of this research has focused on such factors as product quality and social responsibility, and not the coordination of the levels of occupational health and safety and other factors involving enterprises in the manufacturing supply chain.

To sum up, firstly, although the work safety behavior of SMEs is considered from the perspective of the supply chain of core enterprises, measures are mainly proposed from the macro and qualitative levels, and there is little quantitative research, especially the introduction of work-safety-level parameters into the work safety management of the supply chain. Secondly, most studies only focus on the decisionmaking types among supply chain node enterprises, and lack of in-depth research on the relationship between core enterprises and SMEs, and how to give full play to the incentive and restraint role of core enterprises on work safety of SMEs. In addition, there is a lack of comparison, segmentation, and discussion of different types of supply chain decisionmaking behavior in the existing research. 
Therefore, this paper considers a perspective given the influence of enterprises' occupational health and work safety on the equilibrium results across the manufacturing supply chain. This is particularly significant in the work's construction and analysis of supply chain node-enterprises' optimal operational decisions in both centralized and decentralized decisions. By comparing the total profit and safety levels in the two decisions, the work examines the need to coordinate contracts in core enterprises; this benefits the supply chain by increasing not only occupational health and safety levels but also total profit. Finally, revenue- and costsharing contracts are used to enhance the supply chain's total profit and occupational health and safety levels in centralized decision-making. Furthermore, the supply chain node-enterprises' profits also improve, and the entire system can reach an optimal level.

Compared with the above studies, this paper has the following innovations:

Firstly, the paper describes the scientific proposition of multisubject participation in work safety management of manufacturing SMEs and deeply discusses how the core enterprises occupying the leading position in the supply chain transmit their own work safety pressures from the society to manufacturing SMEs to further provide theoretical support for the feasibility and effectiveness of work safety management of the supply chain through the incentive and constraint strategies established with SMEs.

Secondly, it integrates the core enterprises of the supply chain in the Chinese context to participate in the research on the work safety management of SMEs and helps SMEs reduce their safety costs and improve their work safety level by establishing the Stackelberg game of the core enterprises in the supply chain on the work safety behavior of manufacturing SMEs in the country. Then, the problem of how core enterprises effectively control the work safety of manufacturing SMEs is solved.

Finally, the paper focuses on the overall work safety level of the manufacturing supply chain and analyses the optimal operation decisions of the node enterprises in the supply chain when making centralized and decentralized decisions. The impact of the cooperation mode of benefit sharing and cost sharing on the work safety level and total profit of the supply chain is established and the dynamics of the supply chain environment and the complexity of multisubject behavior and its interaction are brought into focus.

\section{Model Hypothesis and Research Method Solution}

3.1. Model Assumptions. This research aims to address the current situation involving work safety in the core enterprises and SMEs in a manufacturing supply chain. Safety economics and supply chain contract theories are used to improve the work safety level of SMEs-and even the entire manufacturing supply chain-by coordinating the supply chain's contracts with the work safety level as a constraint, with the enterprises' occupational health and safety in particular. Specifically, when core enterprises consider significant efforts to improve safety performance of supply chain, SMEs in contrast are focusing on their own profit. However, they should focus on decision-making to enhance the supply chain's occupational health and safety while simultaneously trying to reach their respective goals. According to the complete information game theory, constructing a Stackelberg game model between core enterprises and SMEs-and setting parameters for work safety levels-can provide decision-making support to coordinate and optimize supply chain contracts by designing a benefitdistribution strategy. The following assumptions are made:

(1) A secondary supply chain system $s c$, consisting of SME supplier $s$ and core enterprise manufacturer $m$, is only considered. It is assumed that they are both risk-neutral and fully rational; manufacturers provide products to the market and consumers consider not only price factors in their purchases but also social responsibility factors, such as the enterprise's work safety level. Suppliers and manufacturers make different safety investments to maximize their own returns in response to consumers' sensitivity to prices and work safety levels.

(2) The core enterprises take market demand as the order quantity, purchase raw materials from their SMEs, and then the product quality is confirmed. The market demand positively correlates with the reputation and social responsibility of the core enterprises and SMEs in the supply chain, and particularly to the supply chain enterprises' work safety level.

(3) The core enterprises possess the absolute right to negotiate because of their strength and control over the SMEs' wholesale prices; their orders to the SMEs are indicated by the wholesale price $w$, which does not pertain to the enterprises' work safety level.

(4) When SMEs manufacture a product, the unit cost is $c_{s}\left(c_{s}>0\right)$, or the supplier's unit production cost regardless of work safety; the enterprises' processing cost is $c_{m}\left(c_{m}>0\right)$, which is the manufacturer's unit processing cost regardless of the work safety level.

(5) Under government supervision and social influence, core enterprises and SMEs should achieve a certain level of work safety and pay the cost for such safety efforts. Assuming that the core enterprises have a strong sense of work safety and initiative, and the SMEs' awareness in this respect is insufficient, the SMEs' implementation of various levels of occupational health and work safety processes will affect safety in the entire supply chain. If the SMEs bear the cost of efforts to improve the supply chain's work safety-with the final work safety level expressed as $e$ and the safety input cost function as paid by the SMEs is expressed as $c(e)=k e^{2} / 2$ [38] - then $k>0$ is expressed as the marginal cost coefficient for SMEs' safety input.

(6) A complete information, two-stage game is conducted that involves $s$ and $m$, in which the core enterprise's order quantity equals market demand, the core enterprises provide order quantity $q$ and 
fixed wholesale price $w$, and SMEs subsequently determine the work safety level $e$. The consumer market demand $q$ is a linear function of price $p$ and work safety level $e[39,40]$, expressed as $q=a-$ $b p+r e, a>0, b>0, r>0$, where $a$ represents the market size independent of the product price and the work safety level, $b$ represents the consumer's price sensitivity coefficient, and $r$ represents the consumer's occupational health and safety sensitivity coefficient. Collectively, these reflect the consumer's awareness of enterprises' occupational health and work safety level.

3.2. Model Parameter Description. Based on the previously discussed assumptions, the relevant parameters of the core enterprises, SMEs, and manufacturing supply chain are shown in Table 1:

Based on the above definitions and assumptions, the profit objective functions of core enterprises, SMEs, and the entire supply chain can be expressed as follows, respectively:

$$
\begin{aligned}
& \pi_{m}=\left(p-w-c_{m}\right) q=\left(p-w-c_{m}\right)(a-b p+r e), \\
& \pi_{s}=\left(w-c_{s}\right) q-\frac{1}{2} k e^{2}=\left(w-c_{s}\right)(a-b p+r e)-\frac{1}{2} k e^{2}, \\
& \pi_{s c}=\left(p-c_{s}-c_{m}\right) q-\frac{1}{2} k e^{2}=\left(p-c_{s}-c_{m}\right)(a-b p+r e)-\frac{1}{2} k e^{2} .
\end{aligned}
$$

In the above formulas, the profits of the core enterprises, SMEs, and the entire supply chain are, respectively, expressed as $\pi_{m}, \pi_{s}$, and $\pi_{s c}$.

\subsection{Research Methodology}

3.3.1. Centralized Decision in the Manufacturing Supply Chain. With complete information, the manufacturing supply chain's centralized decision consists of close cooperation between core enterprises and SMEs in the entire manufacturing supply chain. In such a relationship, they have common goals and jointly pursue the maximization of the supply chain's overall interests. This provides significant advantages in both work safety and cost controls to the core enterprises and SMEs with long-term cooperative relationships, or in situations in which SMEs attach to a certain core enterprise. Therefore, the centralized decision in the manufacturing supply chain is as follows: to first determine the levels of work safety $e$ and product price $p$, and then sell products in the market. The manufacturing supply chain's profit function is as follows:

$$
\pi_{s c}^{c}=\left(p-c_{s}-c_{m}\right) q-\frac{1}{2} k e^{2}=\left(p-c_{s}-c_{m}\right)(a-b p+r e)-\frac{1}{2} k e^{2},
$$

According to Song et al. [29], assuming $2 b k-r^{2}>0$, obtain the manufacturing supply chain's optimal work safety level $e^{c}$ and product price $p^{c}$ under the centralized decision, as follows (see the deduction process in Appendix A):

$$
\begin{aligned}
& e^{c}=\frac{r\left[a-b\left(c_{s}+c_{m}\right)\right]}{2 b k-r^{2}}, \\
& p^{c}=\frac{a k+\left(b k-r^{2}\right)\left(c_{s}+c_{m}\right)}{2 b k-r^{2}} .
\end{aligned}
$$

At this point, the equilibrium market demand is

$$
q^{c}=a-b p+r e=\frac{b k\left[a-b\left(c_{s}+c_{m}\right)\right]}{2 b k-r^{2}} .
$$

Formulas (3) and (4) are substituted into Formula (2) to obtain the equilibrium profit in the case of the manufacturing supply chain's centralized decision, as follows:

$$
\pi_{s c}^{c}=\frac{k\left[a-b\left(c_{s}+c_{m}\right)\right]^{2}}{2\left(2 b k-r^{2}\right)} .
$$

Although the centralized decision is the result of a balanced profit decision under rational conditions, it does not indicate that the centralized decision is the best cooperative coordination mechanism. Generally, the distribution of profits among supply-chain node enterprises is difficult to reasonably realize, and the decentralized decision is applied more often. Therefore, it is difficult to realize centralized decision in the actual manufacturing supply chain.

\subsubsection{Decentralized Decision in the Manufacturing Supply} Chain. Under the decentralized decision, SMEs' suppliers and the core enterprises' manufacturers are rational, independent entities that pursue their own maximum interests and independently determine their own levels of work safety. Consequently, a master-slave game exists between the core enterprises and Stackelberg SMEs, as follows. The core enterprises face the consumer market and make decisions according to market demand. They determine product prices $p$; SMEs consider these product prices in choosing the appropriate wholesale price $w$, and work safety level $e$. Meanwhile, the profit objective function of the core enterprises and SMEs in the manufacturing supply chain under the decentralized decision is calculated as follows:

$$
\begin{aligned}
\pi_{m}^{d} & =\left(p-w-c_{m}\right) q=\left(p-w-c_{m}\right)(a-b p+r e), \\
\pi_{s}^{d} & =\left(w-c_{s}\right) q-\frac{1}{2} k e^{2}=\left(w-c_{s}\right)(a-b p+r e)-\frac{1}{2} k e^{2} .
\end{aligned}
$$

Obtain the equilibrium safe production level $e^{d}$ and wholesale price $w^{d}$ of SMEs' input under the decentralized decision, as follows (see the deduction process in Appendix B):

$$
\begin{aligned}
e^{d} & =\frac{r\left[a-b\left(c_{s}+c_{m}\right)\right]}{4 b k-r^{2}}, \\
w^{d} & =\frac{2 k\left(a+b c_{s}-b c_{m}\right)-r^{2} c_{s}}{4 b k-r^{2}} .
\end{aligned}
$$

Determine the core enterprises' optimal product price, as follows: 
TABLE 1: Meaning of the relevant parameters.

\begin{tabular}{lc}
\hline Parameters & Meaning \\
\hline$w$ & Wholesale prices for SME suppliers, $w>0$ \\
$p$ & Product price, $p>0$ \\
$c_{s}$ & SME suppliers' production cost, $c_{s}>0$ \\
$c_{m}$ & Work safety level, $e>0$ \\
$e$ & Core enterprise manufacturer's processing cost, $c_{m}>0$ \\
$k$ & Marginal cost coefficient for safety inputs, $k>0$ \\
$q$ & Market demand \\
$a$ & Market size, $a>0$ \\
$b$ & Consumer's price sensitivity coefficient, $b>0$ \\
$r$ & Consumer's occupational health and safety sensitivity coefficient, $r>0$ \\
$\pi$ & Profit function \\
$\lambda$ & Safety cost-sharing coefficient \\
$\theta$ & Revenue distribution coefficient \\
\hline Subscripts of all parameters & SME suppliers \\
$s$ & Core enterprise manufacturers \\
$m$ & Supply chain \\
$s c$ & Centralized decision \\
\hline Superscripts of all parameters & Decentralized decision \\
$c$ & Revenue-sharing contract \\
$d$ & Revenue- and cost-sharing contract \\
$r s$ & and
\end{tabular}

$$
p^{d}=\frac{3 a k+\left(b k-r^{2}\right)\left(c_{s}+c_{m}\right)}{4 b k-r^{2}} .
$$

At this point, the product demand is

$$
q^{d}=a-b p+r e=\frac{b k\left[a-b\left(c_{s}+c_{m}\right)\right]}{4 b k-r^{2}} .
$$

Formulas (9)-(11) are substituted into Formulas (7) and (8) to obtain the equilibrium profits for each decision subject in the case of the manufacturing supply chain's decentralized decision, as follows:

$$
\begin{aligned}
\pi_{m}^{d} & =\frac{b k^{2}\left[a-b\left(c_{s}+c_{m}\right)\right]^{2}}{\left(4 b k-r^{2}\right)^{2}}, \\
\pi_{s}^{d} & =\frac{k\left[a-b\left(c_{s}+c_{m}\right)\right]^{2}}{2\left(4 b k-r^{2}\right)}, \\
\pi_{s c}^{d} & =\frac{k\left[a-b\left(c_{s}+c_{m}\right)\right]^{2}\left(6 b k-r^{2}\right)}{2\left(4 b k-r^{2}\right)^{2}} .
\end{aligned}
$$

3.3.3. Analysis of the Balanced Results from the Centralized and Decentralized Decisions. Table 2 lists the equilibrium results of the centralized and decentralized decisions in the manufacturing supply chain under complete rationality. The equilibrium results are then compared and analyzed to provide further explanation.

Proposition 1 (safety level). The work safety level in the decentralized decision is lower than that in the centralized decision, or $e^{d}<e^{c}$ (see the proof process in Appendix C).
Proposition 1 shows that centralized decision-making takes the supply chain as a whole, which will greatly improve the work safety level of the supply chain when pursuing the maximization of total interests. The higher the willingness $r^{2} / b k$ of safety investment, the greater the improvement of the work safety level of the supply chain by centralized decision-making.

Proposition 2 (product price). The relationship between product price $p^{d}$ and product price $p^{c}$ in the decentralized decision depends on the value of $b k-r^{2}$ when $b k>r^{2}$, $p^{d}>p^{c}$; when $b k<r^{2}, p^{d}<p^{c}$; and when $b k=r^{2}, p^{d}=p^{c}$ (see the proof process in Appendix D).

Proposition 2 shows that when the willingness of safety investment $r^{2} / b k$ is relatively low, the expansion effect of the small increase of work safety level on market demand is not obvious. Therefore, the market competition is still dominated by price competition. At this time, the product price under centralized decision-making is lower than that under decentralized decision-making. When the safety investment intention $r^{2} / b k$ is relatively high, the market generally has high work safety awareness, so it will prefer to choose products with higher work safety levels. According to the change of consumer demand preference, the market competition will change from traditional price competition to work safety level competition. At this time, the increase of total profit of supply chain enterprises mainly comes from the stimulation of work safety levels on market demand.

Proposition 3 (market demand). Market demand under the decentralized decision situation is lower than that under the centralized decision situation, or $q^{d}<q^{c}$ (see the proof process in Appendix E). 
TABLE 2: Supply chain equilibrium results in different decision situations.

\begin{tabular}{lcc}
\hline Parameters & Centralized decision $(c)$ & Decentralized decision $(d)$ \\
\hline$e$ & $e^{c}=r\left[a-b\left(c_{s}+c_{m}\right)\right] /\left(2 b k-r^{2}\right)$ & $e^{d}=r\left[a-b\left(c_{s}+c_{m}\right)\right] /\left(4 b k-r^{2}\right)$ \\
$p$ & $p^{c}=\left[a k+\left(b k-r^{2}\right)\left(c_{s}+c_{m}\right)\right] /\left(2 b k-r^{2}\right)$ & $p^{d}=\left[3 a k+\left(b k-r^{2}\right)\left(c_{s}+c_{m}\right)\right] /\left(4 b k-r^{2}\right)$ \\
$q$ & $q^{c}=b k\left[a-b\left(c_{s}+c_{m}\right)\right] /\left(2 b k-r^{2}\right)$ & $q^{d}=b k\left[a-b\left(c_{s}+c_{m}\right)\right] /\left(4 b k-r^{2}\right)$ \\
$\pi_{s}$ & - & $\pi_{s}^{d}=k\left[a-b\left(c_{s}+c_{m}\right)\right]^{2} / 2\left(4 b k-r^{2}\right)$ \\
$\pi_{m}$ & - & $\pi_{m}^{d}=b k^{2}\left[a-b\left(c_{s}+c_{m}\right)\right]^{2} /\left(4 b k-r^{2}\right)^{2}$ \\
$\pi_{s c}$ & $\pi_{s c}^{c}=k\left[a-b\left(c_{s}+c_{m}\right)\right]^{2} / 2\left(2 b k-r^{2}\right)$ & $\pi_{s c}^{d}=k\left[a-b\left(c_{s}+c_{m}\right)\right]^{2}\left(6 b k-r^{2}\right) / 2\left(4 b k-r^{2}\right)^{2}$ \\
\hline
\end{tabular}

Proposition 3 shows that when the upstream and downstream enterprises of the supply chain form centralized decision-making, they can significantly improve the total market demand and the overall welfare level of the market and the willingness of safety investment $r^{2} / b k$ will amplify the positive effect of centralized decision-making on market welfare.

Proposition 4. (total profit). The core enterprises' and SMEs' total profit under the decentralized decision are lower than that of the supply chain under the centralized decision, or $\pi_{s}^{d}+\pi_{m}^{d}=\pi_{s c}^{d}<\pi_{s c}^{c}$, and the supply chain's total profit under the decentralized decision is less than three-fourths of the total profit under the centralized decision (see the proof process in Appendix F).

Proposition 4 shows that the greater the growth of the overall profits of the supply chain and the profits of each member brought by centralized decision-making, the easier it is to stimulate the enthusiasm of upstream and downstream enterprises in the supply chain to seek cooperation. Finally, the appropriate contract mechanism is chosen to realize the coordination of the shipping supply chain.

Given this analysis, the supply chain's work safety level, market demand, and overall profit under the decentralized decision are all lower than those in the centralized decision, which also discourages SMEs' work safety investments in the supply chain. More reasonable coordination contracts need to be designed to encourage supply chain members' active participation and improve each member's balanced results. Therefore, contract coordination is needed to not only guide both core enterprises' and SMEs' decisions but also to improve the supply chain's occupational health and safety.

3.3.4. Revenue-Sharing Contract Coordination. Supply chain enterprises' equilibrium results can reach a level under the centralized decision to maximize the supply chain system's decision variables through coordinated revenuesharing contracts. In the following, such contracts are incorporated to enhance cooperation between core enterprises and SMEs, and achieve equilibrium results.

While SMEs can reach a basic level of work safety standards to a certain extent under the decentralized decision, chaos may still exist in long-term cooperation with core enterprises that violates occupational health and safety-related laws and regulations, such as a poor working environment, the risk of occupational diseases, or employment that violates labor laws, among others. In the absence of a contract, "double marginalization" will lead core enterprises and SMEs to choose decentralized decisions that are detrimental to occupational health and safety. Therefore, core enterprises can invoke various processes in decision-making to coordinate the supply chain. For example, such enterprises can further improve their cooperative relationships with SMEs by reasonably considering wholesale prices and order quantities in their purchasing processes. Furthermore, core enterprises can compensate the SMEs with part of their own resources to enable them to retain a certain level of profits and inspire them to further improve their work safety.

In setting the revenue distribution coefficient to $\theta$, the model assumes the following: $\theta \in[0,1]$, in that when $\theta=1$, it belongs to the decentralized decision situation, and SMEs do not share any of the core enterprises' revenue; when $\theta=0$, the SMEs obtain all the core enterprises' revenue, which can be regarded as the centralized decision; and when $\theta \in[0,1]$, this indicates the contract-coordination situation. When the core enterprise and its SMEs reach a revenue-sharing agreement, the core enterprise retains its sales revenue ratio $\theta$, and the rest will be returned to the SMEs according to the contract. The SMEs will determine their best level of work safety $e^{r s}$ according to their own profit maximization, while the core enterprises will determine the optimal product price $p^{r s}$ according to their own profit maximization. At this time, the core enterprises' and SMEs' profit objective functions while coordinating a revenue-sharing contract are expressed as follows, respectively:

$$
\begin{aligned}
& \pi_{m}^{r s}=\left(\theta p-w-c_{m}\right)(a-b p+r e), \\
& \pi_{s}^{r s}=\left[(1-\theta) p+w-c_{s}\right](a-b p+r e)-\frac{1}{2} k e^{2} .
\end{aligned}
$$

According to the definition of supply chain contract coordination [41], the revenue-sharing contract is implemented to ensure that the SMEs' and core enterprises' decision variables under a coordinated contract reach the level under the centralized decision, or to simultaneously satisfy $p^{r s}=p^{c}$ and $e^{r s}=e^{c}$.

Formula (14) calculates the first derivative of $p$ and makes it zero to obtain the product price that maximizes the core enterprise's profit:

$$
p^{r s}=\frac{\theta(a+r e)+b\left(w+c_{m}\right)}{2 b \theta} .
$$

With $\quad p^{r s}=\left[\theta(a+r e)+b\left(w+c_{m}\right)\right] / 2 b \theta=[(a+r e)+$ $\left.b\left(c_{s}+c_{m}\right)\right] / 2 b=p^{c}$, the optimal wholesale price is obtained as: 


$$
w^{r s}(\theta)=\theta\left(c_{s}+c_{m}\right)-c_{m} .
$$

Formulas (16) and (17) are substituted into Formula (15) to obtain the first-order partial derivative of $e$, which is set as zero to get the work safety level for the optimal input:

$$
e^{r s}=\frac{r(1-\theta)\left[a-b\left(c_{s}+c_{m}\right)\right]}{2 b k-r^{2}(1-\theta)} .
$$

Proposition 5. Regardless of the value of $\theta$, the SMEs' optimal level of work safety is still lower than that of the centralized decision, and the supply chain cannot effectively coordinate; when $\theta<0.5$, a coordinated revenue-sharing contract can stimulate SMEs' work safety levels.

Proof. To compare $e^{r s}$ and $e^{c}$ and obtain a different value between $e^{r s}$ and $e^{c}$ :

$$
e^{r s}-e^{c}=-\frac{2 b k r \theta\left[a-b\left(c_{s}+c_{m}\right)\right]}{\left(2 b k-r^{2}\right)\left[2 b k-r^{2}(1-\theta)\right]} .
$$

As $\theta \in(0,1)$ and $e^{r s}-e^{c}<0$ under the revenue-sharing contract, the optimal work safety investment from SME suppliers is still lower than that under the centralized decision, and thus, the supply chain cannot effectively coordinate.

The optimal work safety level $e^{r s}$ under the revenuesharing contract is then compared with the optimal work safety level $e^{d}$ under the decentralized decision to obtain the difference in value between $e^{r s}$ and $e^{d}$ :

$$
e^{r s}-e^{d}=-\frac{2 b k r(1-2 \theta)\left[a-b\left(c_{s}+c_{m}\right)\right]}{\left(4 b k-r^{2}\right)\left[2 b k-r^{2}(1-\theta)\right]} .
$$

If $\theta \in(0,0.5)$ and $e^{r s}-e^{d}>0$, or specifically, when SMEs obtain half of their benefits shared with their core enterprises, then the optimal work safety level under the revenuesharing contract is higher than the work safety level under the decentralized decision. Furthermore, the coordinated revenue-sharing contract can encourage SMEs to increase their work safety investments. If $\theta \in(0.5,1)$ and $e^{r s}-e^{d}<0$ -in that the optimal work safety level under the revenuesharing contract is even lower than that under the decentralized decision because the excessively low revenuesharing cannot compensate for the benefit from increasing wholesale prices and solely bearing all work safety cost$s$ - then the SMEs' revenue will decrease. Consequently, SMEs will refuse to accept this type of contract coordination.

In considering the manufacturing supply chain's work safety constraints, it can be observed that the revenuesharing contract has a limited incentive effect on improving SME suppliers' work safety. Although SMEs can obtain part of their core enterprises' distributed benefits, they must still bear the total cost of work safety investments, and cannot fully mobilize their resources to improve safety levels.

\subsubsection{A Coordination Analysis of Revenue- and Cost-Sharing} Contracts. Core enterprises and SMEs should adopt a positive cooperative approach to further optimize the effects of coordinating contracts and achieve an ideal state involving the centralized decision variables. In such an approach, the core enterprises should consider sharing SMEs' safety input costs based on revenue-sharing contracts; specifically, they should further strengthen their cooperative relationship with SMEs while ensuring that the latter's levels of work safety reach a basic threshold. Moreover, core enterprises should regard their supplier SMEs as an extension of themselves and consider various safety and cost input factors, improving occupational and employee health, further encouraging and supporting SMEs by enhancing their access to audit preferences, providing guidance on safety training and technical service cooperation, and even establishing work safety incentives [11]. Such measures would further reduce SMEs' safety input costs and encourage them to improve their levels of work safety. Under revenue- and cost-sharing contract coordination, and assuming that the core enterprises' shared safety cost coefficient is $\lambda \in(0,1)$ and the given revenue distribution coefficient is $\theta \in(0,1)$, the core enterprises' and SMEs' profit objective functions in the supply chain are, respectively [42]:

$$
\begin{aligned}
& \pi_{m}^{r c}=\left(\theta p-w-c_{m}\right)(a-b p+r e)-\frac{1}{2} \lambda k e^{2}, \\
& \pi_{s}^{r c}=\left[(1-\theta) p+w-c_{s}\right](a-b p+r e)-\frac{1}{2}(1-\lambda) k e^{2} .
\end{aligned}
$$

Proposition 6. Under the coordinated revenue- and costsharing contract, when the contract variable parameters $(w, \theta$, $\lambda)$ between the core enterprises and SMEs meet the conditions of $w^{r c}(\theta)=\theta\left(c_{s}+c_{m}\right)-c_{m}$, with $\theta=\lambda \in\left[2 b k\left(2 b k-r^{2}\right) /\right.$ $\left.\left(4 b k-r^{2}\right)^{2}, 2 b k /\left(4 b k-r^{2}\right)\right]$, then the supply chain is perfectly coordinated (see the proof process in Appendix G).

When $\theta=\lambda \in\left[2 b k\left(2 b k-r^{2}\right) /\left(4 b k-r^{2}\right)^{2}, 2 b k /(4 b k-\right.$ $\left.r^{2}\right)$ ], the revenue- and cost-sharing contract can finally realize the Pareto improvement in both sides' profits. Consequently, core enterprises and SMEs can coordinate their appropriate contract parameters $(w, \theta$, and $\lambda)$ to reach an optimal level of work safety. These SMEs can also be encouraged to improve both sides' profits, and to strengthen the stable cooperation from manufacturing supply-chain node enterprises. The specific $\theta$ value primarily depends on the bargaining power of the core enterprises and their SMEs, but this value must benefit both sides and realize coordination in the supply chain.

\section{Model Analysis}

Through the model analysis, the research aims to obtain "double marginalization" in supply chain work safety, and proposes the revenue- and cost-sharing contract model. The research conclusions' validity is further verified through a numerical simulation, and each sensitivity coefficient's effects on the work safety level and the supply chain's total profit are analyzed. The simulation takes a market demand scale of $a=100$, customer price sensitivity coefficient of 
$b=5$, occupational health and customer safety sensitivity coefficient of $r=2$, core enterprises' processing cost of $c_{m}=1$, and SMEs' production costs of $c_{s}=7$.

\subsection{Supply Chain Optimal Decision and Profit Analysis under} Different Decision Models. The optimal decision variables and profits of the supply chain members under the four models-the centralized decision, decentralized decision, revenue-sharing contract, and revenue- and cost-sharing contract-can be obtained by setting $k=2$ as equal to the marginal cost coefficient for the safety input and the revenue distribution coefficient $\theta=0.4$, as shown in Table 3:

(1) Table 3 indicates that the optimal level of work safety and the total profit of the supply chain node enterprises under the revenue- and cost-sharing contract are higher than those of the revenue-sharing contract and the decentralized decision

(2) As $\theta<0.5$, the product price under the decentralized decision is higher than that under the centralized decision, while the supply chain's level of work safety, market demand, and total profit are less than those under the centralized decision and revenuesharing contract

\subsection{Impact Analysis of the $k, b$, and $r$ Sensitivity Factors on the Level of Work Safety}

4.2.1. Impact of Marginal Cost Factor $k$ Safety Input on the Work Safety Level $(k \longrightarrow e)$. Figure 1 demonstrates that with the increase of the safety input's marginal cost coefficient, the supply chain's level of work safety decreases in three cases. With the same marginal cost coefficient for the safety input, work safety is the highest under the revenue- and costsharing contract, followed by the level under the revenuesharing contract; work safety in the supply chain is the lowest under the decentralized decision [42]. Under the decentralized decision, the core enterprises and SMEs each make decisions independently to maximize their own interests. At this time, the SMEs solely bear the safety investment costs, and such investments are clearly insufficient. By coordinating the revenue- and cost-sharing contract, the core enterprises and SMEs form a community of interests in the manufacturing supply chain, and core enterprises share more safety costs than those under the revenue-sharing contract. The SMEs' work safety efforts also increase, which can further improve the supply chain's level of work safety.

\subsubsection{Impact of Consumer Price Sensitivity $b$ on Work Safety} Levels $(b \longrightarrow e)$. Figure 2 reveals that increasing the consumer price sensitivity coefficient decreases the supply chain's level of work safety in three cases. As consumers are sensitive to product prices, they will inevitably tend to purchase at lower prices; thus, core enterprises will reduce their prices to retain consumers according to the increase in consumers' price sensitivities. Therefore, SMEs under market demand will not increase their products' cost to improve the level of work safety, resulting in high product prices. Under the decentralized decision, core enterprises and SMEs decrease their total cost to maximize their own profits. Through the revenue- and cost-sharing contract, the core enterprises' and SMEs' gaming produce the revenuesharing and the cost-sharing factor, while the SMEs obtain a certain level of revenue. Therefore, the SMEs' work safety efforts also increase, which will improve the supply chain's work safety.

\subsubsection{Impact of Consumers' Occupational Health and Safety} Sensitivity Coefficient $r$ on the Work Safety Level $(r \longrightarrow e)$. Figure 3 indicates that increasing the consumers' occupational health and safety sensitivity coefficient increases the supply chain's level of work safety in three cases. This is because the higher the consumers' occupational health and safety sensitivity coefficient, the higher the work safety's sensitivity to the enterprises' profits. At this time, SMEs will increase their work safety by increasing their safety investments; at a certain threshold, the consumer's occupational health and safety sensitivity coefficient increases, while SMEs are slow to improve the level of work safety. However, when the sensitivity coefficient exceeds this threshold, this accelerates SMEs' speed to improve safety efforts. Under the same occupational health and safety sensitivity coefficient, the suppliers' work safety level decreases in turn under three modes: the revenue- and cost-sharing contract, revenuesharing contract, and decentralized decision. This indicates that the revenue- and cost-sharing contract can cause SMEs' work safety to reach the supply chain's level under the centralized decision, which effectively improves the supply chain's work safety level.

\subsection{Impact Analysis of the $k, b$, and $r$ Sensitivity Coefficients on the Entire Supply Chain's Profits}

4.3.1. Impact of Safety Input Marginal Cost Coefficient $k$ on the Supply Chain Profits $\left(k \longrightarrow \pi_{s c}\right)$. Figure 4 demonstrates that increasing the safety input marginal cost coefficient decreases the supply chain's total profit in three cases. According to the previous analysis, the level of supply chain work safety decreases when increasing the safety input marginal cost coefficient. Thus, the core enterprises can decrease the quantity purchased from SMEs with low safety levels as much as possible to reduce the losses from enterprises' safety accidents or occupational health problems. Subsequently, product market demand will decrease when the safety input marginal cost coefficient increases; meanwhile, given the relationship between supply and demand, the wholesale price decreases. Given a decrease in the core enterprises' market demand and wholesale price, the SMEs' profits will also decrease. Based on this analysis, the supply chain's profit will decrease with an increase in the safety input marginal cost coefficient.

4.3.2. Impact of Consumer Price Sensitivity Coefficient $b$ on the Supply Chain's Profits $\left(b \longrightarrow \pi_{s c}\right.$ ). Figure 5 demonstrates that as the consumer price sensitivity coefficient increases, 
TABLE 3: Supply chain optimal decision and profit analysis under different decision models.

\begin{tabular}{lcccccc}
\hline Decision forms & $e$ & $p$ & $q$ & $w$ & $\pi_{s}$ & $\pi_{m}$ \\
\hline Centralized decision $(c)$ & 7.5 & 15.5 & 37.5 & - & - & - \\
Decentralized decision $(d)$ & 3.33 & 18 & 16.67 & 13.67 & 100 & 55.56 \\
Revenue-sharing contract $(r s)$ & 4.09 & 14.82 & 34.09 & 2.2 & 122.73 & 92.98 \\
Revenue- and cost-sharing contract $(r c)$ & 7.5 & 15.5 & 37.5 & 2.2 & 135 & 90.56 \\
\hline
\end{tabular}

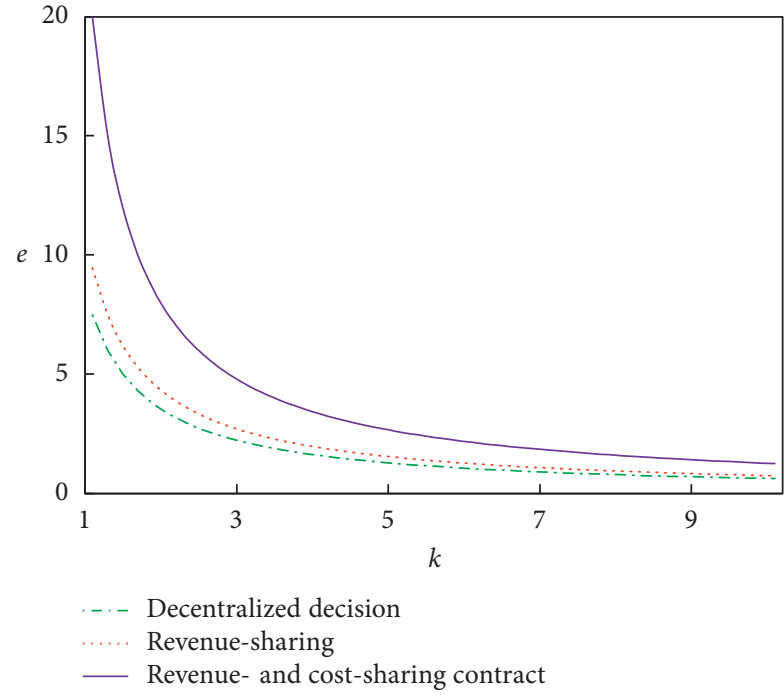

Figure 1: Effects of the safety input's marginal cost coefficient on the work safety level.

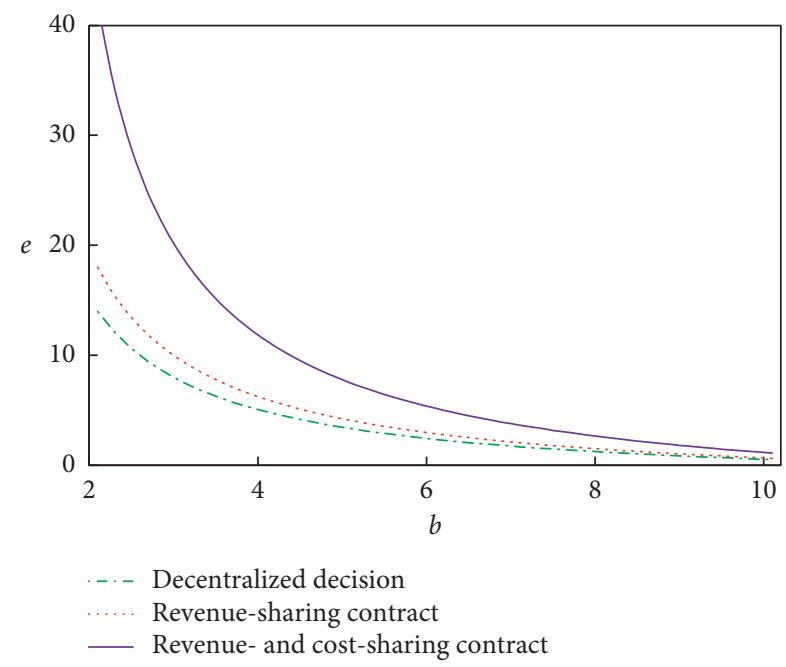

FIGURE 2: Impact of consumer price sensitivity factors on work safety levels.

the supply chain's total profit decreases in three cases. The previous analysis reveals that the supply chain's work safety will decrease with an increase in the consumers' price sensitivity coefficient. As customers tend to reduce purchase quantities, this will decrease product occupational health and work safety and other social responsibilities caused by utility losses. Therefore, the market demand for products will decrease with the increasing consumer price sensitivity

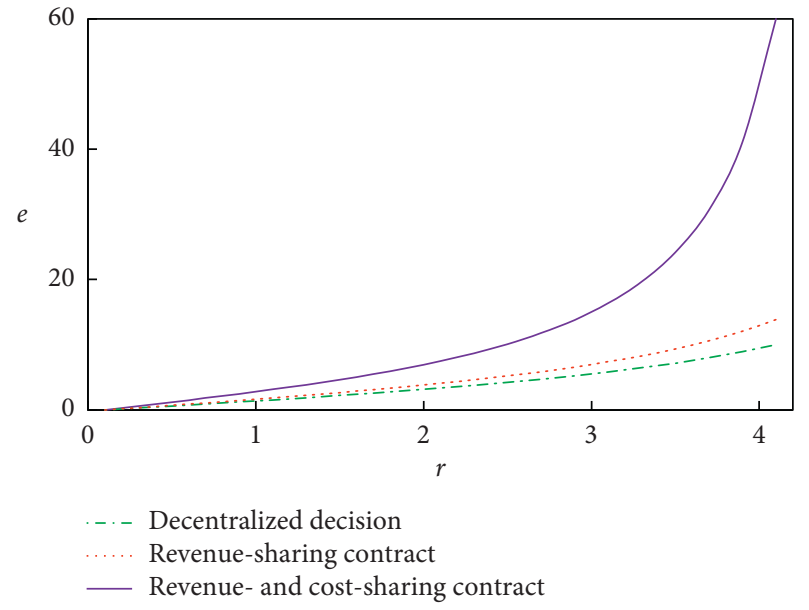

FIgURE 3: Impact of consumers' occupational health and safety sensitivity coefficient on work safety.

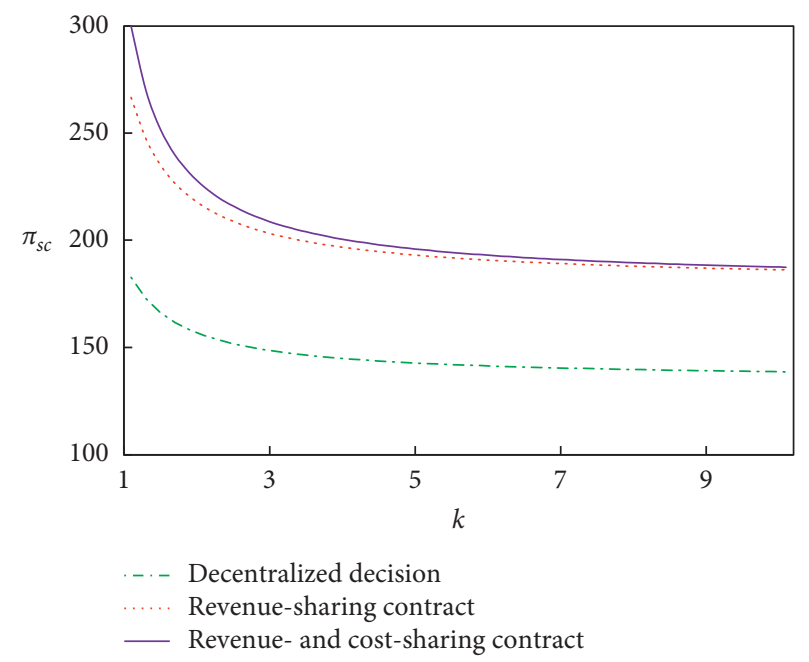

FIGURE 4: Impact of the safety input marginal cost coefficient on the supply chain's profits.

coefficient. Simultaneously, the relationship between supply and demand will influence the product price to also decrease, resulting in the core enterprises' and SMEs' declining profits. This comprehensive analysis indicates that the supply chain's total revenue decreases with the increase in the consumer price sensitivity coefficient.

4.3.3. Impact of Consumer Occupational Health and Safety Sensitivity Coefficient $r$ on Supply Chain Profits $\left(r \longrightarrow \pi_{s c}\right)$. 


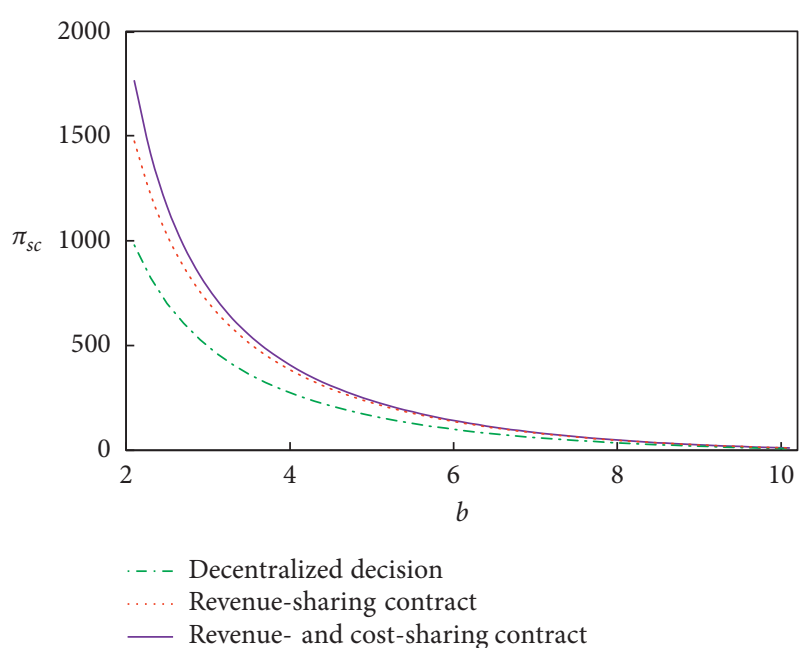

FIgURE 5: The consumer price sensitivity coefficient's impact on the supply chain's profits.

Figure 6 reveals that with the increasing consumer occupational health and safety sensitivity coefficient, the supply chain's total profit increases in three cases. The higher the consumer occupational health and safety coefficient's sensitivity, the more sensitive it is to increases in the supply chain's profit. At this time, SMEs will increase the core enterprises' profit by increasing their safety investments to a certain threshold. When the consumer's occupational health and safety sensitivity coefficient increases, the supply chain slowly increases its profit, but when the threshold is exceeded, the supply chain's total profit increases faster. Under the same consumer occupational health and safety sensitivity coefficient, the supplier's total profit decreases in turn under three modes: the revenue- and cost-sharing contract, revenue-sharing contract, and decentralized decision. This indicates that the revenue- and cost-sharing contract can cause the supply chain's profit to reach the same level as with the centralized decision, which can effectively improve the supply chain's profit.

\subsection{Analysis of the Revenue-Sharing Coefficient's $\theta$ and Decision Variables}

4.4.1. Impact of the Revenue-Sharing Factor $\theta$ on Work Safety Level $(\theta \longrightarrow e)$. Figure 7 demonstrates that the work safety level under the revenue-sharing contract decreases with the increase of the revenue-sharing coefficient $\theta$. This is because core enterprises using revenue-sharing contracts provide SMEs with revenue due to the increased safety cost input, which encourages SMEs to improve their safety levels. When $\theta<0.5$, SMEs gain more than half of the core enterprises' revenue, and the revenue-sharing contract can encourage SMEs to improve their work safety. When $\theta>0.5$, the low revenue-sharing ratio cannot compensate for the wholesale price increase, and cannot solely bear the total cost of work safety investments. At this time, the safety level is even lower than that under the decentralized decision. Under the revenue- and cost-sharing condition, the manufacturing

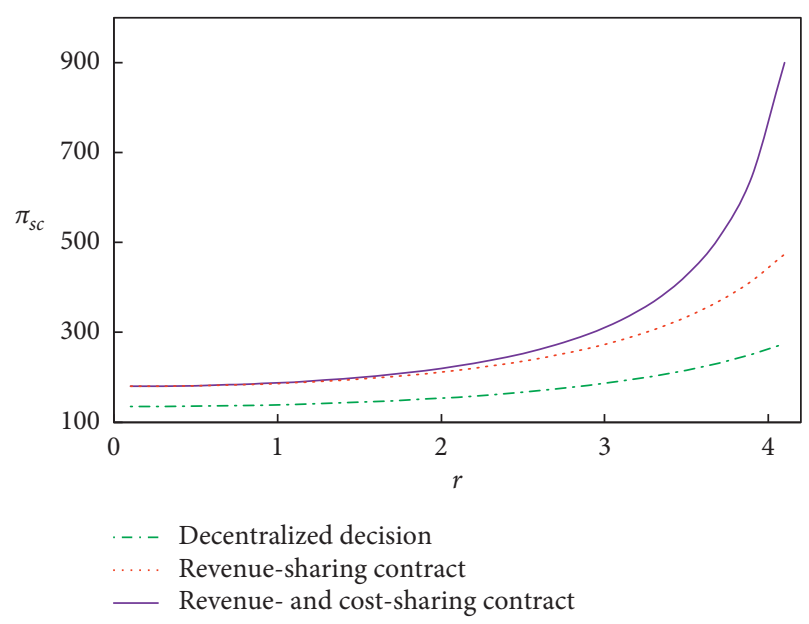

FIGURE 6: Impact of consumer occupational health and safety sensitivity coefficient on supply chain profits.

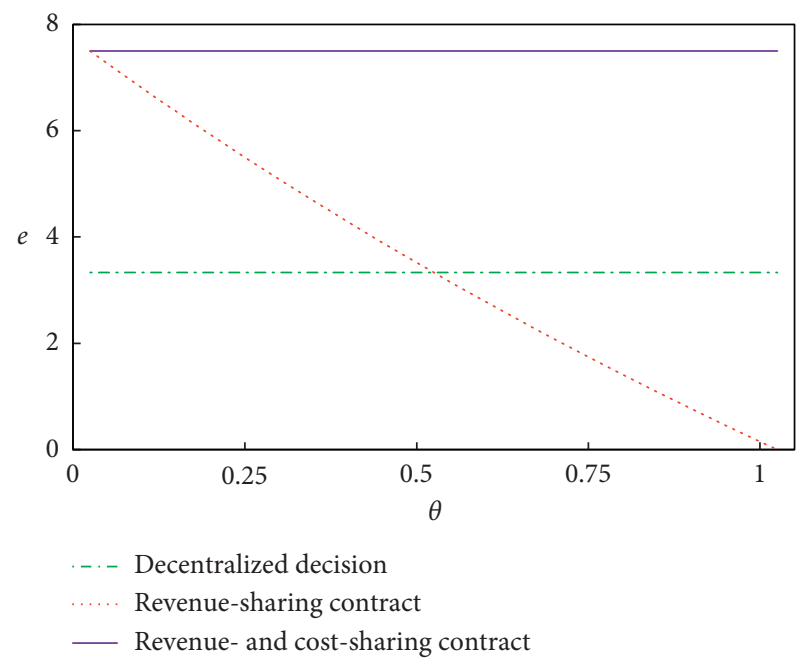

FIGURE 7: Impact of revenue-sharing coefficient on the work safety level.

supply chain's work safety level is always higher than that under the decentralized decision and revenue-sharing contract; this indicates that the cost-sharing mechanism has a more obvious incentive effect to compel SMEs to improve their work safety.

4.4.2. Impact of Revenue-Sharing Coefficient $\theta$ on Supply Chain Profits $\left(\theta \longrightarrow \pi_{s c}\right)$. Figure 8 reveals that regardless of the value of $\theta$, the manufacturing supply chain's total profit under the revenue-sharing contract is always greater than that of the decentralized decision and the revenue-sharing contract. The supply chain's profit under the revenuesharing contract decreases with the increase in the revenuesharing coefficient $\theta$, but is always larger than the profit from the decentralized decision. This is because the core enterprises under the revenue- and cost-sharing contract share the benefits from compensating for the safety cost input to 


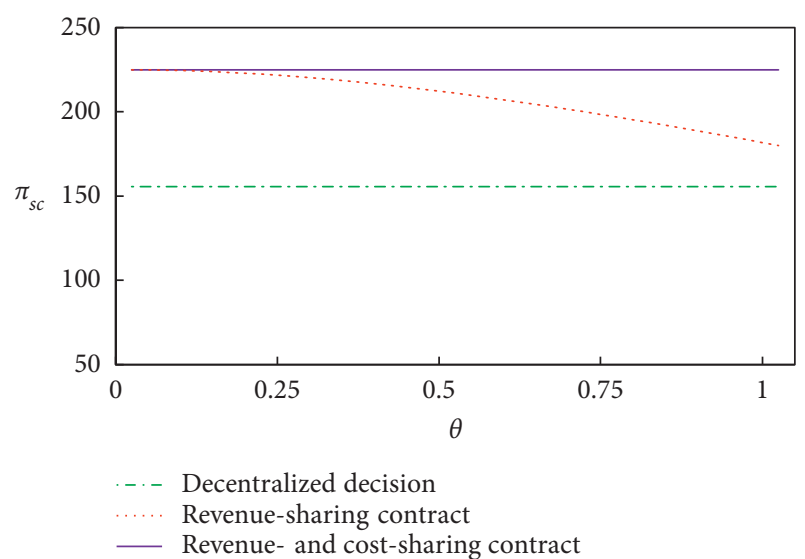

FIGURE 8: Impact of revenue-sharing coefficient on the supply chain's profits.

the SMEs to encourage them to improve their safety levels. Thus, the core enterprises and SMEs can increase the supply chain's profits while improving safety.

It can be observed that introducing a cost-sharing mechanism to the supply chain is a clearer method to promote profit. In the actual production in the manufacturing supply chain, two aspects primarily determine whether core enterprises and SMEs reach the revenueand cost-sharing contract coordination: one is the core enterprises' bargaining power, and the other is the judgment from market demand. If enterprises operate in a market in which consumers can effectively identify the levels of work safety and occupational health-and improving the enterprises' safety can obviously stimulate market demand-then the core enterprises will be willing to not only accept certain profit losses in exchange for higher wholesale prices but also maintain long-term cooperative relationships with their SMEs.

4.4.3. Impact of Revenue-Sharing Coefficient $\theta$ on the Profits of Both Core Enterprises and SMEs $(\theta \longrightarrow \pi)$. Figure 9 presents the case of the revenue- and cost-sharing contract, in which the revenue distribution coefficient and costsharing coefficient $\theta$ of the core enterprises gradually increase. In this case, the SMEs' profit gradually decreases, and the core enterprises' profit gradually increases. Therefore, core enterprises are also willing to maintain cooperative relationships with SMEs, and bear certain safety input costs in exchange for more benefits. When the coefficient reaches a certain value, the core enterprises and SMEs realize a Pareto-type improvement.

This figure also reveals the $\theta$ value's impact on the core enterprises' and SMEs' profits when $\theta=\lambda=0.4$, both before and after the supply chain contracts' coordination. According to the present post-coordination calculation, when $\theta \in[0.247,0.556]$, the core enterprises and SMEs realize a Pareto improvement. Specifically, the core enterprises accept the contract on the premise of at least $24.7 \%$ revenue regardless of consumer preference; furthermore, the core enterprises can gain only $55.6 \%$ of this revenue at most to

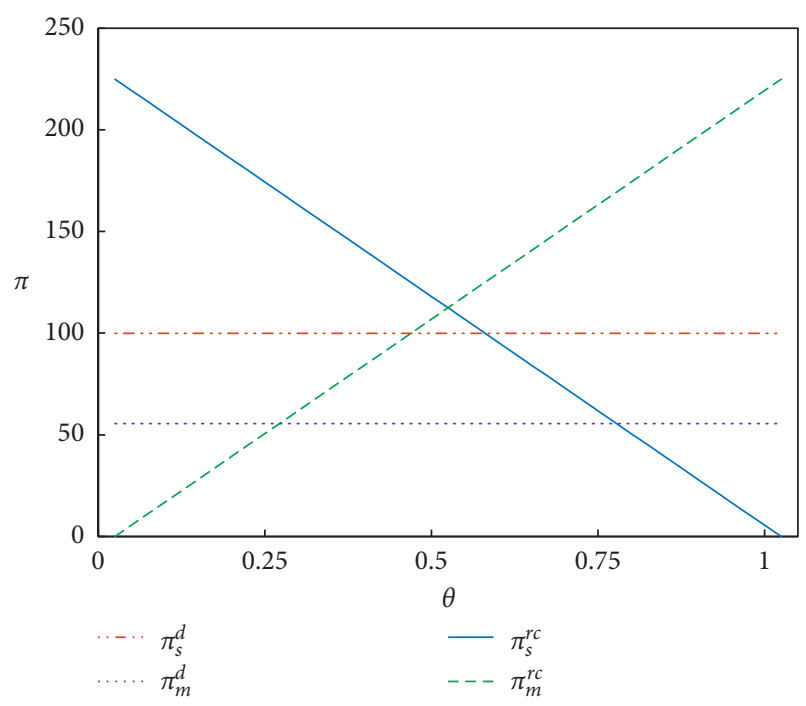

FIgURE 9: The revenue-sharing coefficient's impact on the profits of core enterprises and SMEs.

ensure that the SMEs' profits are not affected. Consequently, consumer utility as well as the supply chain's occupational health and safety levels also improve.

\section{Conclusions}

Supply chain occupational safety and health management have attracted great attention among enterprises. This study considers the secondary supply chain of core enterprises and SMEs to establish a Stackelberg game model that compares and analyses the equilibrium results for the manufacturing supply chain under the centralized and decentralized decisions. Simultaneously, the study extends prior research that indicates the contract-coordinating revenue and all equilibrium indexes in the supply chain reach the centralized decision level under the revenue- and cost-sharing contract. Ultimately, the results provide the following conclusions:

(1) Given the optimal decision and profit analysis of a supply chain under different decision models, the levels of work safety and total profits are lower than with the revenue-sharing contract when supplychain node enterprises incorporate the decentralized decision. When the revenue- and cost-sharing contract is selected, the SMEs' and core enterprises' profits are also higher than with the decentralized decision. Furthermore, the work safety level and overall target profits for each node enterprise in the manufacturing supply chain will increase accordingly, and the state illustrates the optimal result.

(2) Given the impact-analysis model of the sensitivity coefficient's effects on the work safety level, the three circumstances-decentralized decision, revenuesharing contract, and revenue- and cost-sharing contract-will cause the following situations. First, the supply chain's level of work safety decreases with the increase in the safety input marginal cost coefficient and consumers' price sensitivity coefficient, 
and increases with an increase in the consumers' occupational health and safety sensitivity coefficient. Second, the work safety level under the same sensitivity coefficient increases in the three previously discussed circumstances in turn. Third, in coordinating the revenue- and cost-sharing contract, the core enterprises and SMEs form an interest community in the manufacturing supply chain-the SMEs will attempt to improve their own work safety, then that of the entire supply chain.

(3) The influence analysis model of the sensitivity coefficient's effects on the total supply chain's profit indicates that the following situations will occur in the three circumstances (the decentralized decision, revenue-sharing contract, and revenue- and costsharing contract): First, the total supply chain's profit decreases with the increase in the safety input marginal cost coefficient and consumers' price sensitivity coefficient, and increases with an increase in consumers' occupational health and safety sensitivity coefficient. Second, under the same sensitivity coefficient, the suppliers' total profit increases in the three modes in turn under the same sensitivity coefficient. Third, in coordinating the revenue- and cost-sharing contract, the core enterprises and SMEs form the interest community in the manufacturing supply chain as they reach a centralized decision state, thus enhancing the supply chain's overall profit.

(4) Based on the revenue-sharing contract, the supply chain's equilibrium profit and work safety level cannot reach the centralized decision situation, and cannot realize the supply chain coordination, but the revenue- and cost-sharing contract mechanism can realize a mutually beneficial result for both the core enterprises and SMEs. Furthermore, such partnerships can realize an equilibrium in the supply chain's work safety, product prices, and profit under the centralized decision.

\section{Management Implications}

According to the Stackelberg game model, core enterprises and SMEs in the supply chain are analyzed based on their decision models, work safety levels, and profits [43]. By examining the results obtained from different experimental models, we obtain the following management implications.

First, we should pay attention to the leading position that core enterprises hold in the supply chain, emphasize the initiatives they take, establish a supplier safety management system, and ensure that the work safety of suppliers and other related parties is under control of the internal management of core enterprises.
Second, under the decision choices of the supply chain, supply chain node enterprises should choose the revenueand cost-sharing contract as far as possible; this will not only increase profits and market demand and reduce product prices but, most importantly, will also improve work safety levels, especially in the case of SMEs.

Third, in the supply chain environment, if the core enterprises are able to incur more safety costs, SMEs will improve their own work safety levels as much as possible, reducing the emergence of safety accidents and employee occupational health and safety problems. This will improve the overall quality of the supply chain, reduce the risk of supply chain interruptions, improve supply chain node enterprises' reputations, and increase profits.

Fourth, in the context of revenue-sharing contracts, supply chain node enterprises still have "double marginalization," that is, a synchronous increase of profits, increase of work safety levels, reduction of prices, and so on. Therefore, supply chain node enterprises, especially core enterprises, need to actively communicate and negotiate with SMEs, which, in turn, should actively cooperate with core enterprises' coordination strategy as far as possible and then obtain a revenue- and cost-sharing contract.

\section{Limitations and Future Developments}

Based on an analysis of the Stackelberg game model, this paper expands the different decisions under the four situations: the centralized decision, decentralized decision, revenue-sharing contract, and revenue- and cost-sharing contract. However, three limitations exist:

This paper assumes that each node enterprise is riskneutral. The random demand market considers the influence from the loss aversion caused by the core enterprises' shortages and backlogs on the enthusiasm toward work safety investments; one limitation of this research involves how to incorporate this kind of factor into research on the incentive problem surrounding node enterprises' safety investments.

Another limitation is the deterministic demand function, which is used to describe the market demand, as only the price and work safety level constraints are considered as factors affecting consumers' purchase behaviors. Thus, subsequent studies can introduce factors that affect demand-such as information-sharing, product quality, core enterprises' promotion efforts-or consider the influence of multiple, simultaneous factor combinations.

As this paper only considers the incentive problem of work safety input in a secondary supply chain, future research can focus on consumers' preferences and multi-level supply chain coordination, among other related topics, to assist core enterprises and SMEs in conforming to the real market environment. 


\section{Appendix}

\section{A. Equilibrium Value of Centralized Decision}

$$
\pi_{s c}^{c}=\left(p-c_{s}-c_{m}\right) q-\frac{1}{2} k e^{2}=\left(p-c_{s}-c_{m}\right)(a-b p+r e)-\frac{1}{2} k e^{2} .
$$

The first-order partial derivatives for $p$ and $e$ are then obtained, as

$$
\begin{aligned}
& \frac{\partial \pi_{s c}^{c}}{\partial p}=-2 b p+r e+a+b\left(c_{s}+c_{m}\right), \\
& \frac{\partial \pi_{s c}^{c}}{\partial e}=r p-k e-r\left(c_{s}+c_{m}\right) .
\end{aligned}
$$

The second-order partial and mixed partial derivatives of $p$ and $e$ are obtained in Formulas (A.2) and (A.3), respectively.

$$
\begin{aligned}
& \frac{\partial^{2} \pi_{s c}^{c}}{\partial p^{2}}=-2 p \\
& \frac{\partial^{2} \pi_{s c}^{c}}{\partial e^{2}}=-k \\
& \frac{\partial^{2} \pi_{s c}^{c}}{\partial p \partial e}=\frac{\partial^{2} \pi_{s c}^{c}}{\partial e \partial p}=r
\end{aligned}
$$

Hence, a second-order Hessian matrix is obtained under the centralized decision, as follows:

$$
H^{c}(p, e)=\left[\begin{array}{ll}
\frac{\partial^{2} \pi_{s c}^{c}}{\partial p^{2}} & \frac{\partial^{2} \pi_{s c}^{c}}{\partial p \partial e} \\
\frac{\partial^{2} \pi_{s c}^{c}}{\partial e \partial p} & \frac{\partial^{2} \pi_{s c}^{c}}{\partial e^{2}}
\end{array}\right]=\left[\begin{array}{cc}
-2 b & r \\
r & -k
\end{array}\right] .
$$

Given the first-order principal minor of the matrix $-2 b<0, \quad \partial^{2} \pi_{s c}^{c} / \partial p \partial e=\partial^{2} \pi_{s c}^{c} / \partial e \partial p=r>0$, assuming $2 b k$ $-r^{2}>0$, the second-order Hessian matrix is negative and definite, with a unique optimal solution $e^{c}$ and $p^{c}$ under the centralized decision.

Formulas (A.2) and (A.3) are then combined to obtain the manufacturing supply chain's optimal work safety level $e^{c}$ and product price $p^{c}$ under the centralized decision:

$$
\begin{aligned}
e^{c} & =\frac{r\left[a-b\left(c_{s}+c_{m}\right)\right]}{2 b k-r^{2}}, \\
p^{c} & =\frac{a k+\left(b k-r^{2}\right)\left(c_{s}+c_{m}\right)}{2 b k-r^{2}} .
\end{aligned}
$$

\section{B. Equilibrium Value of Decentralized Decision}

$$
\begin{aligned}
& \pi_{m}^{d}=\left(p-w-c_{m}\right) q=\left(p-w-c_{m}\right)(a-b p+r e) \\
& \pi_{s}^{d}=\left(w-c_{s}\right) q-\frac{1}{2} k e^{2}=\left(w-c_{s}\right)(a-b p+r e)-\frac{1}{2} k e^{2} .
\end{aligned}
$$

As $\partial^{2} \pi_{m}^{d} / \partial p^{2}=-2 b<0$, the core enterprise profit function $\pi_{m}^{d}$ is the concave function of the product price $p$, where

$$
\frac{\partial \pi_{m}^{d}}{\partial p}=a+r e+b\left(w+c_{m}\right)-2 b q=0 .
$$

The product price to maximize the core enterprise's profit is

$$
p^{d}=\frac{a+r e+b\left(w+c_{m}\right)}{2 b} .
$$

Formula (B.4) is substituted into the SMEs' profit objective function in Formula (B.2) to obtain

$$
\pi_{s}^{d}=\frac{\left(w-c_{s}\right)\left[a+r e-b\left(w+c_{m}\right)\right]-k e^{2}}{2} .
$$

The second-order partial derivatives for $w$ and $e$ are obtained as $\partial^{2} \pi_{s}^{d} / \partial w^{2}=-b<0$ and $\partial^{2} \pi_{s}^{d} / \partial e^{2}=-k<0$, in which we can observe their concave functions. The secondorder Hessian matrix is

$$
H^{d}(w, e)=\left[\begin{array}{ll}
\frac{\partial^{2} \pi_{s}^{d}}{\partial w^{2}} & \frac{\partial^{2} \pi_{s}^{d}}{\partial w \partial e} \\
\frac{\partial^{2} \pi_{s}^{d}}{\partial e \partial w} & \frac{\partial^{2} \pi_{s}^{d}}{\partial e^{2}}
\end{array}\right]=\left[\begin{array}{cc}
-b & \frac{r}{2} \\
\frac{r}{2} & -k
\end{array}\right] .
$$

As the first-order principal minor of the matrix $-b<0$, $\partial^{2} \pi_{s}^{d} / \partial w \partial e=\partial^{2} \pi_{s}^{d} / \partial e \partial w=r / 2>0$ when $4 b k-r^{2}>0$ and the second-order Hessian matrix is negative and definite, then $w^{d}, e^{d}$, and $p^{d}$ are the unique optimal solutions under the decentralized decision, where $\partial \pi_{s}^{d} / \partial w=0, \partial \pi_{s}^{d} / \partial e=0$, or

$$
\begin{array}{r}
r e-2 b w+a+b\left(c_{s}-c_{m}\right)=0, \\
2 k e-r w+r c_{s}=0 .
\end{array}
$$

Formulas (B.7) and (B.8) are combined to obtain the equilibrium safe production level $e^{d}$ and wholesale price $w^{d}$ of SMEs' input under the following decentralized decision:

$$
\begin{aligned}
e^{d} & =\frac{r\left[a-b\left(c_{s}+c_{m}\right)\right]}{4 b k-r^{2}}, \\
w^{d} & =\frac{2 k\left(a+b c_{s}-b c_{m}\right)-r^{2} c_{s}}{4 b k-r^{2}} .
\end{aligned}
$$




\section{Safety Level Comparison}

Proof process of Proposition 1:

According to Table 2,

$$
\frac{e^{d}}{e^{c}}=\frac{2 b k-r^{2}}{4 b k-r^{2}}=1-\frac{2 b k}{4 b k-r^{2}}<1 \text {, so } e^{d}<e^{c} .
$$

\section{Product Price Comparison}

Proof process of Proposition 2:

According to Table 2,

$$
p^{d}-p^{c}=\frac{2 k\left[a-b\left(c_{s}+c_{m}\right)\right]\left(b k-r^{2}\right)}{\left(2 b k-r^{2}\right)\left(4 b k-r^{2}\right)} .
$$

As $2 b k-r^{2}>0,4 b k-r^{2}>0$, and $a-b\left(c_{s}+c_{m}\right)>0$; thus, the relationship between $2 k\left[a-b\left(c_{s}+c_{m}\right)\right]$ $\left(b k-r^{2}\right) /\left(2 b k-r^{2}\right)\left(4 b k-r^{2}\right)$ and 0 depends on the value of $b k-r^{2}$ :

(1) When $b k>r^{2}$, then $p^{d}>p^{c}$

(2) When $b k>r^{2}$, then $p^{d}>p^{c}$

(3) When $b k>r^{2}$, then $p^{d}>p^{c}$

\section{E. Market Demand Comparison}

Proof process of Proposition 3:

According to Table 2,

$$
\frac{q^{d}}{q^{c}}=\frac{2 b k-r^{2}}{4 b k-r^{2}}=1-\frac{2 b k}{4 b k-r^{2}}<1 \text {, so } q^{d}<q^{c}
$$

\section{F. Total Profit Comparison}

Proof process of Proposition 4:

According to Table 2,

$$
\begin{aligned}
\frac{\pi_{s c}^{d}}{\pi_{s c}^{c}} & =\frac{\left(2 b k-r^{2}\right)\left(6 b k-r^{2}\right)}{\left(4 b k-r^{2}\right)^{2}}=1-\frac{4 b^{2} k^{2}}{\left(4 b k-r^{2}\right)^{2}}<1-\frac{4 b^{2} k^{2}}{(4 b k)^{2}} \\
& =\frac{3}{4}, \text { or } \pi_{s c}^{d}<\frac{3}{4} \pi_{s c}^{c} .
\end{aligned}
$$

\section{G. Equilibrium Value of Revenue- and Cost- Sharing Contracts}

Proof process of Proposition 6:

$$
\begin{gathered}
\pi_{m}^{r c}=\left(\theta p-w-c_{m}\right)(a-b p+r e)-\frac{1}{2} \lambda k e^{2} . \\
\pi_{s}^{r c}=\left[(1-\theta) p+w-c_{s}\right](a-b p+r e)-\frac{1}{2}(1-\lambda) k e^{2} .
\end{gathered}
$$

Following the previously mentioned solution, the core enterprises' and SMEs' decision variables under contract coordination must simultaneously reach the centralized decision level to perfectly coordinate the supply chain, or specifically, $p^{r c}=p^{c}, e^{r c}=e^{c}$.

Formula (G.1) is used to find the first-order partial derivative of $p$ and make it zero. If the product price function $p^{r c}$ obtained from maximizing the core enterprise's profit is consistent with Formula (16) then $p^{r c}=p^{c}$ to obtain the optimal wholesale price:

$$
w^{r c}(\theta)=\theta\left(c_{s}+c_{m}\right)-c_{m} .
$$

Substituting Formulas (16) and (G.3) into the SMEs' objective profit function in Formula (G.2) and setting $\partial \pi_{s}^{r c} / \partial e=0$ provides the work safety level under optimal input:

$$
e^{r c}=\frac{r(1-\theta)\left[a-b\left(c_{s}+c_{m}\right)\right]}{2 b k(1-\lambda)-r^{2}(1-\theta)} .
$$

If $e^{r c}=r(1-\theta)\left[a-b\left(c_{s}+c_{m}\right)\right] / \quad\left[2 b k(1-\lambda)-r^{2}(1-\right.$ $\theta)]=r\left[a-b\left(c_{s}+c_{m}\right)\right] /\left(2 b k-r^{2}\right)=e^{c}$, then:

$$
\theta=\lambda
$$

Substituting Formulas (A.6), (A.7), (G.3), and (G.5) into Formulas (G.1) and (G.2) provides the core enterprises', SMEs' and the supply chain's profits, respectively, as

$$
\begin{aligned}
& \pi_{m}^{r c}=\frac{k \theta\left[a-b\left(c_{s}+c_{m}\right)\right]^{2}}{2\left(2 b k-r^{2}\right)}, \\
& \pi_{s}^{r c}=\frac{k(1-\theta)\left[a-b\left(c_{s}+c_{m}\right)\right]^{2}}{2\left(2 b k-r^{2}\right)}, \\
& \pi_{s c}^{r c}=\pi_{m}^{r c}+\pi_{s}^{r c}=\frac{k\left[a-b\left(c_{s}+c_{m}\right)\right]^{2}}{2\left(2 b k-r^{2}\right)}=\pi_{s c}^{c} .
\end{aligned}
$$

Pareto's optimal improvement can be achieved by simultaneously satisfying $\left\{\begin{array}{l}\pi_{m}^{r c} \geq \pi_{m}^{d} \\ \pi_{s}^{r c} \geq \pi_{s}^{d}\end{array}\right.$ and combining Formulas (13) and (G.6) and (G.7); that is,

$$
\left\{\begin{array}{l}
\frac{k \theta\left[a-b\left(c_{s}+c_{m}\right)\right]^{2}}{2\left(2 b k-r^{2}\right)} \geq \frac{b k^{2}\left[a-b\left(c_{s}+c_{m}\right)\right]^{2}}{\left(4 b k-r^{2}\right)^{2}} \\
\frac{k(1-\theta)\left[a-b\left(c_{s}+c_{m}\right)\right]^{2}}{2\left(2 b k-r^{2}\right)} \geq \frac{k\left[a-b\left(c_{s}+c_{m}\right)\right]^{2}}{2\left(4 b k-r^{2}\right)}
\end{array}\right.
$$

The range of contract parameters can be obtained as

$$
\theta \in\left[\frac{2 b k\left(2 b k-r^{2}\right)}{\left(4 b k-r^{2}\right)^{2}}, \frac{2 b k}{4 b k-r^{2}}\right] .
$$

\section{Data Availability}

The data used to support the findings of this study are available from the corresponding author upon request. 


\section{Conflicts of Interest}

The authors declare that there are no conflicts of interest regarding the publication of this paper.

\section{Acknowledgments}

This research was funded by the National Natural Science Foundation of China under Grant nos. 71874072, 72074099, and 72004081; Jiangsu Province Social Science Foundation under Grant no. 20GLB009; China Postdoctoral Science Foundation under Grant no. 2020M671378; and Postgraduate Research and Practice Innovation Program of Jiangsu Province under Grant no. KYCX18_2211.

\section{References}

[1] D. J. Ketchen and L. C. Giunipero, "The intersection of strategic management and supply chain management," Industrial Marketing Management, vol. 33, no. 1, pp. 51-56, 2004.

[2] Q. M. Zhou, Q. Mei, S. X. Liu, and Q. W. Wang, "Dual-effects of core enterprise management and media attention on occupational health and safety of small and medium suppliers in China," Technology in Society, vol. 63, 2020.

[3] C. R. Carter, "Purchasing social responsibility and firm performance," International Journal of Physical Distribution and Logistics Management, vol. 35, no. 3, pp. 177-194, 2005.

[4] C. Mayhew and M. Quinlan, "Subcontracting and occupational health and safety in the residential building industry," Industrial Relations Journal, vol. 28, no. 3, pp. 192-205, 2010.

[5] S. Chopra and M. S. Sodhi, "Managing risk to avoid supplychain breakdown," MIT Sloan Management Review, vol. 46, no. 1, pp. 53-61, 2004.

[6] C. Speier, J. M. Whipple, D. J. Closs, and M. D. Voss, "Global supply chain design considerations: mitigating product safety and security risks," Journal of Operations Management, vol. 29, no. 7, pp. 721-736, 2011.

[7] T. Fabian, "Supply chain management in an era of social and environment accountability," Sustainable Development International, no. 2, pp. 27-30, 2000.

[8] P. R. Kleindorfer and G. H. Saad, "Managing disruption risks in supply chains," Production and Operations Management, vol. 14, no. 1, pp. 53-68, 2005.

[9] I. L. Nunes, "The nexus between OSH and subcontracting," Work, vol. 41, pp. 3062-3068, 2012.

[10] X. M. Luo and J. Ren, "Optimal supply diversification strategy under supply disruption," Mathematical Problems in Engineering, vol. 2020, Article ID 8686371, 18 pages, 2020.

[11] C. X. Guo, X. S. Li, and Y. H. Guo, "Coordination and profit sharing strategies for supply chains to perform corporate social responsibilities," Journal of Industrial Engineering and Management, vol. 25, no. 2, pp. 107-112, 2011.

[12] P. James, R. Johnstone, M. Quinlan, and D. Walters, "Regulating supply chains to improve health and safety," Industrial Law Journal, vol. 36, no. 2, pp. 163-187, 2007.

[13] J. Chen and H. Q. Bai, "Analysis on the reasons of social responsibility management deficiency of multinational corporations' supply chain based on PDCA model-a case study of Apple Company," in Proceedings of the 2016 6th International Conference on Management, Education, Information and Control, vol. 135, pp. 1137-1142, Shenyang, China, May 2016.
[14] H. Vafa Arani, M. Rabbani, and H. Rafiei, "A revenue-sharing option contract toward coordination of supply chains," International Journal of Production Economics, vol. 178, pp. 42-56, 2016.

[15] D. E. Cantor, "Workplace safety in the supply chain: a review of the literature and call for research," International Journal of Logistics Management, vol. 19, no. 1, pp. 65-83, 2008.

[16] D. Walters and P. James, "What motivates employers to establish preventive management arrangements within supply chains?" Safety Science, vol. 49, no. 7, pp. 988-994, 2011.

[17] D. E. Boyd, R. E. Spekman, J. W. Kamauff, and P. Werhane, "Corporate social responsibility in global supply chains: a procedural justice perspective," Long Range Planning, vol. 40, no. 3, pp. 341-356, 2007.

[18] C.-F. Hsueh and M.-S. Chang, "Equilibrium analysis and corporate social responsibility for supply chain integration," European Journal of Operational Research, vol. 190, no. 1, pp. 116-129, 2008.

[19] D. B. Ni, K. W. Li, and X. W. Tang, "Social responsibility allocation in two-echelon supply chains: insights from wholesale price contracts," European Journal of Operational Research, vol. 207, no. 3, pp. 1269-1279, 2010.

[20] D. Zohar, Y.-h. Huang, J. Lee, and M. M. Robertson, “Testing extrinsic and intrinsic motivation as explanatory variables for the safety climate-safety performance relationship among long-haul truck drivers," Transportation Research Part F: Traffic Psychology and Behaviour, vol. 30, pp. 84-96, 2015.

[21] J. Mullen, E. K. Kelloway, and M. Teed, "Employer safety obligations, transformational leadership and their interactive effects on employee safety performance," Safety Science, vol. 91, pp. 405-412, 2017.

[22] R. Locke, M. Amengual, and A. Mangla, "Virtue out of necessity? Compliance, commitment, and the improvement of labor conditions in global supply chains," Politics and Society, vol. 37, no. 3, pp. 319-351, 2009.

[23] R. C. Sinclair, T. R. Cunningham, and P. A. Schulte, "A model for occupational safety and health intervention diffusion to small businesses," American Journal of Industrial Medicine, vol. 56, no. 12, pp. 1442-1451, 2013.

[24] C. Pilbeam, N. Doherty, R. Davidson, and D. Denyer, "Safety leadership practices for organizational safety compliance: developing a research agenda from a review of the literature," Safety Science, vol. 86, pp. 110-121, 2016.

[25] L. Jacxsens, P. A. Luning, J. G. A. J. Van der Vorst, F. Devlieghere, R. Leemans, and M. Uyttendaele, "Simulation modelling and risk assessment as tools to identify the impact of climate change on microbiological food safety - the case study of fresh produce supply chain," Food Research International, vol. 43, no. 7, pp. 1925-1935, 2010.

[26] A. Marucheck, N. Greis, C. Mena, and L. Cai, "Product safety and security in the global supply chain: issues, challenges and research opportunities," Journal of Operations Management, vol. 29, no. 7, pp. 707-720, 2011.

[27] S. Laari, J. Töyli, T. Solakivi, and L. Ojala, "Firm performance and customer-driven green supply chain management," Journal of Cleaner Production, vol. 112, pp. 1960-1970, 2016.

[28] C.-F. Hsueh, "Improving corporate social responsibility in a supply chain through a new revenue sharing contract," International Journal of Production Economics, vol. 151, pp. 214-222, 2014.

[29] H. Song and X. Gao, "Green supply chain game model and analysis under revenue-sharing contract," Journal of Cleaner Production, vol. 170, pp. 183-192, 2018. 
[30] J. M. Cruz, "Dynamics of supply chain networks with corporate social responsibility through integrated environmental decision-making," European Journal of Operational Research, vol. 184, no. 3, pp. 1005-1031, 2008.

[31] A. Hafezalkotob, "Competition of two green and regular supply chains under environmental protection and revenue seeking policies of government," Computers and Industrial Engineering, vol. 82, pp. 103-114, 2015.

[32] Y. Li, C. Wang, G. Li, and C. Chen, "Optimal scheduling of integrated demand response-enabled integrated energy systems with uncertain renewable generations: a Stackelberg game approach," Energy Conversion and Management, vol. 235, Article ID 113996, 2021.

[33] D. Ghosh and J. Shah, "A comparative analysis of greening policies across supply chain structures," International Journal of Production Economics, vol. 135, no. 2, pp. 568-583, 2012.

[34] Q. Zhang, W. Tang, and J. Zhang, "Green supply chain performance with cost learning and operational inefficiency effects," Journal of Cleaner Production, vol. 112, pp. 32673284, 2016.

[35] D. Kannan, K. Govindan, and S. Rajendran, "Fuzzy axiomatic design approach based green supplier selection: a case study from Singapore," Journal of Cleaner Production, vol. 96, pp. 194-208, 2015.

[36] G. P. Cachon and M. A. Lariviere, "Supply chain coordination with revenue-sharing contracts: strengths and limitations," Management Science, vol. 51, no. 1, pp. 30-44, 2005.

[37] T. Chakraborty, S. S. Chauhan, and M. Ouhimmou, "Costsharing mechanism for product quality improvement in a supply chain under competition," International Journal of Production Economics, vol. 208, pp. 566-587, 2019.

[38] S. M. Gilbert and V. Cvsa, "Strategic commitment to price to stimulate downstream innovation in a supply chain," European Journal of Operational Research, vol. 150, no. 3, pp. 617-639, 2003.

[39] H. Gurnani and M. Erkoc, "Supply contracts in manufacturerretailer interactions with manufacturer-quality and retailer effort-induced demand," Naval Research Logistics, vol. 55, no. 3, pp. 200-217, 2008.

[40] W.-G. Zhang, J. H. Fu, J. Fu, H. Li, and W. Xu, "Coordination of supply chain with a revenue-sharing contract under demand disruptions when retailers compete," International Journal of Production Economics, vol. 138, no. 1, pp. 68-75, 2012.

[41] G. P. Cachon, "Supply chain coordination with contracts," Supply Chain Management: Design, Coordination and Operation, vol. 11, no. 11, pp. 227-339, 2003.

[42] G. D. Liu, T. J. Yang, and X. M. Zhang, "Supply chain coordination and decisions under effort-dependent demand and customer balking behaviour," International Journal of Industrial and Systems Engineering, vol. 34, no. 1, pp. 84-106, 2020.

[43] Y. Liu, B.-t. Quan, Q. Xu, and J. Y.-L. Forrest, “Corporate social responsibility and decision analysis in a supply chain through government subsidy," Journal of Cleaner Production, vol. 208, pp. 436-447, 2019. 